
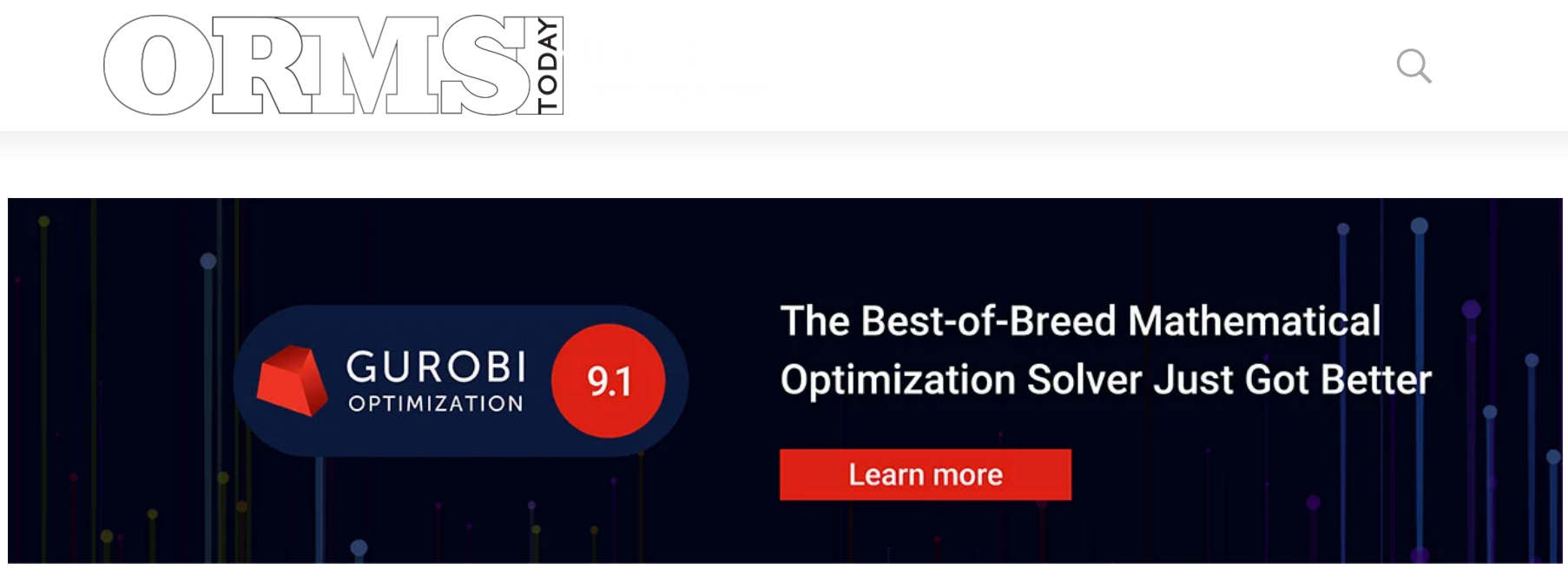

April 12, 2021 in Issues in Education

\title{
The INFORMS Case Competition and the Case for Cases
}

By James J. Cochran, Jeroen Beliën

SHARE: $f$ in $y$

PRINT ARTICLE: 훔

https://doi.org/10.1287/orms.2021.02.18

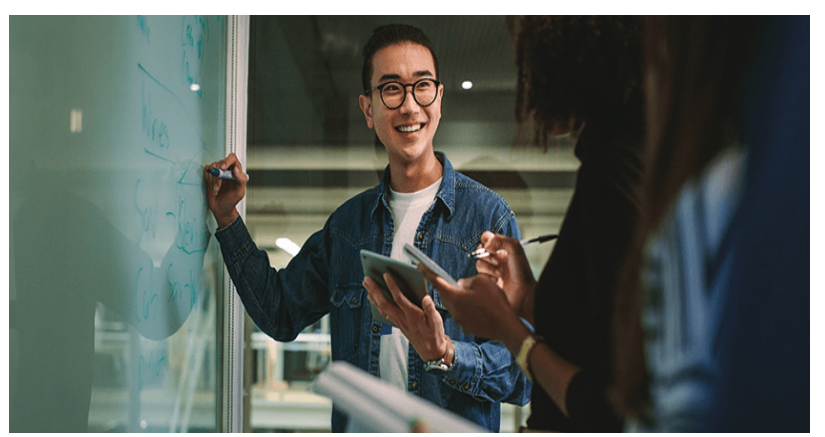

The INFORMS Case Competition was established in 2000 to encourage the creation, dissemination and classroom use of original teaching cases in operations research, management science and analytics. For more than 20 years, the competition has promoted the development and teaching of a diverse collection of cases by INFORMS members across the globe [1]. Many of the winning cases have been published in the journal INFORMS Transactions on Education.

By presenting real-life managerial situations and challenges, teaching cases provide a bridge from the classroom and theory to the workplace and practice. Cases help students at all levels 
experience the challenges of framing problems and thoughtfully applying general principles and sound judgment to reach and defend specific recommended resolutions. Case discussions further enhance the educational experience by providing valuable opportunities for collaborative learning and constructive debate of different perspectives.

Case-based teaching is common practice in many professional degree programs, such as medicine and law, and is standard in some business schools. In analytics programs, use of casebased teaching is more sporadic, although we are observing a general growing trend toward adoption. Indeed, in our own teaching, we have found that hybrid approaches that integrate carefully curated cases with lectures and other classroom formats are more effective than a purely case-based approach. Cases, however, are a cornerstone of teaching applied operations research, management science and analytics courses.

\section{The Case for Cases}

The use of cases is an excellent way for activating education that is crucial for forming passionate, well-educated and critical-thinking professionals. Cases combine the training of analytical skills with the training of soft skills such as group work and presentations. Finally, cases naturally offer multidisciplinary education, e.g., by integrating business decisions with other fields, such as nonprofit applications (healthcare), physics, engineering or new trends in computer science like artificial intelligence and machine learning.

Cases can be obtained from several sources. Many textbooks include cases, and some universities create and sell cases. Some instructors write their own cases (for more on writing original cases, see Cochran [2]), and INFORMS Transactions on Education publishes cases that are free to instructors and students (teaching notes for these cases are also freely available to instructors through a password-protected website). The INFORMS Case Competition provides a means by which instructors who have written original cases can share their efforts with colleagues.

The continued success of the OR/MS/analytics field and profession hinges on getting the next generation of students enthusiastic about it. Developing new cases and sharing them with the world not only contributes to enriching your own teaching but improves education worldwide for students you have never seen or contacted [3]. The impact can't be overestimated.

Through its Case Competition, INFORMS showcases effective original cases, builds a repository of cases and associated teaching notes, expands the library of cases that are freely available to faculty and students (particularly important for our colleagues in developing nations who wish to build or enhance their operations research, management sciences and analytics courses and programs), enables students to gain experience working on real-world problems of a manageable size, and answers those who question the effectiveness of case-based teaching and discussions in analytics education.

\section{The 2021 INFORMS Case Competition}

We invite you to write and submit original cases to this year's INFORMS Case Competition. To learn more about the competition, visit the competition website [1]. All materials must be submitted to the committee through the OpenWater application portal by July 2. A complete submission package will consist of electronic copies of the following: 
- a short (250-500 words) stand-alone abstract;

- the case itself - no more than 10 pages (maximum 3,000 words) single spaced in a 12point proportional font (such as Times New Roman) with one-inch margins (shorter cases are acceptable, and exhibits are in addition to the page limit);

- a teaching note of length and detail as necessary to provide sufficient guidance to potential instructors on how the case could be used in the classroom;

- supplemental files (e.g., datasets); and

- contact information (mailing address, email address and telephone number) for each author of the case.

A panel of judges who are familiar with the case method of teaching will review all submissions to the 2021 INFORMS Case Competition in a blind review process. These judges will select the finalists, and the committee chair will notify all contestants of the judges' decisions by the end of summer 2021. Finalists must present their cases in a special session at the 2021 INFORMS Annual Meeting, Oct. 24-27, to be eligible to win. (For more about what this year's Annual Meeting will look like, read Elena Gerstmann's HQ Highlights column.)

The judges for the 2021 INFORMS Case Competition are Jeroen Belien (KU Leuven, committee chair), Amr Farahat (MIT), Kathryn Schumacher (General Motors), Stefan Creemers (IESEG Lille, France) and Julie Ivy (North Carolina State University).

Note that the following conditions must be met for a case to be eligible for INFORMS Case Competition:

- At least one author of a submission must be a member of INFORMS.

- All submitted cases must be previously unpublished at the time of submission or have first been published within 12 months of the original published submission deadline (July 2, 2021).

Cases should be essentially new in their entirety. If the case contains material originally drafted by individuals or groups other than the author(s) who are submitting the case, the intellectual history and ownership of these portions of the case should be made absolutely clear. Each individual who submits a case for the INFORMS Case Competition is responsible for ensuring that this guideline is strictly met.

The recipient of the first-place prize for the INFORMS Case Competition will be announced at the Awards Ceremony during the 2021 INFORMS Annual Meeting. The finalists will also be encouraged to submit their cases to INFORMS Transactions on Education for peer review and potential publication. The winner will receive $\$ 500$ and an engraved plaque.

The competition committee hopes those who are developing and using original and new teaching cases in their (virtual) classroom will consider submitting cases for the 2021 INFORMS Case Competition. We hope the rest of you will attend the INFORMS Case Competition sessions at the 2021 Annual Meeting. (The presentations in these sessions are always interesting and lively, and they may inspire you to develop teaching cases and perhaps enter them in future INFORMS Case Competitions.) For those unfamiliar with the case method but want to develop a better understanding, we suggest you read Cochran [2, 4], Drake [5] and Penn et al. [6]. 
Questions? Contact the Case Competition Committee chair Jeroen Belien at jeroen.belien@kuleuven.be.

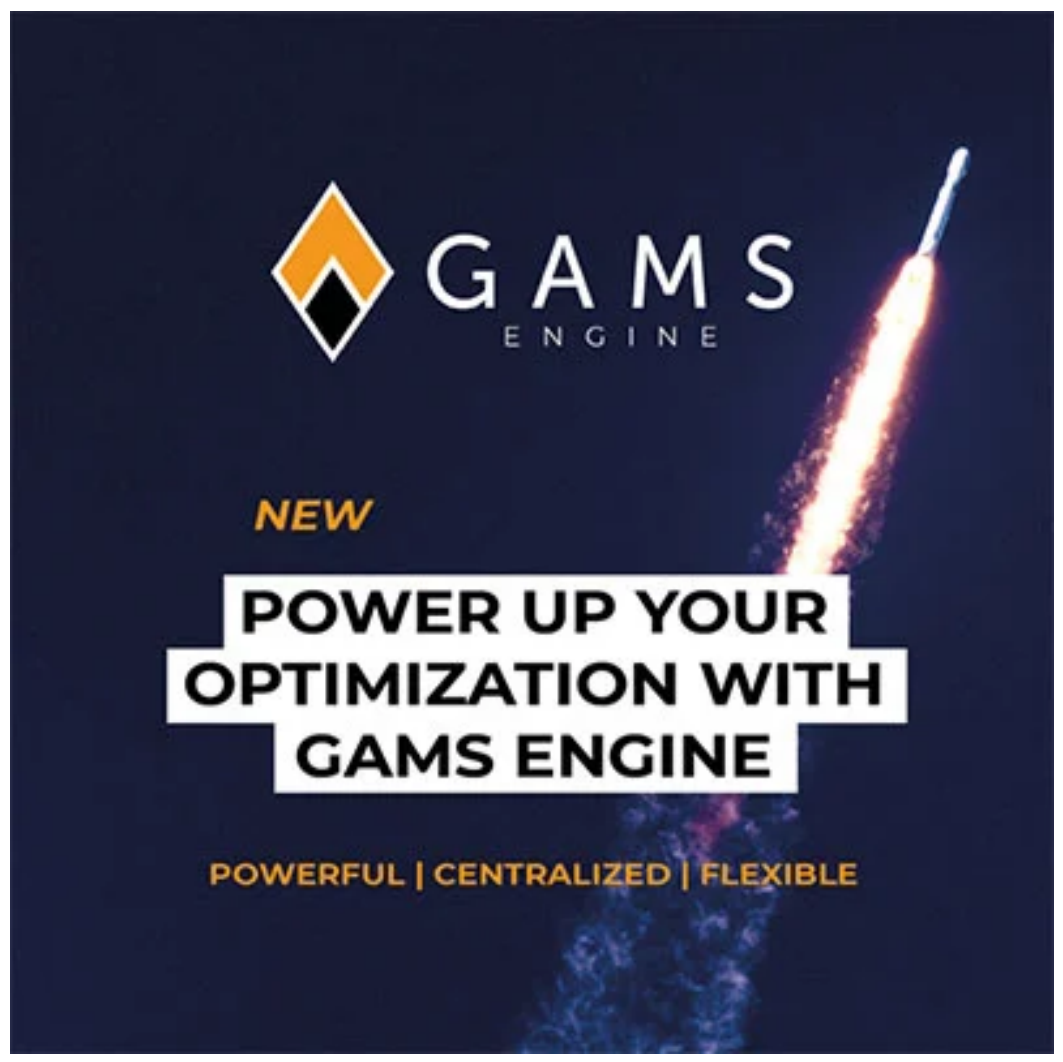

\section{References}

1. https://www.informs.org/Recognizing-Excellence/INFORMS-Prizes/INFORMS-CaseCompetition

2. Cochran, J. J., 2000, "Introductory Business OR Cases: Successful use of Cases in Introductory Undergraduate Business College Operational Research Courses," Journal of the Operational Research Society, Vol. 51, No. 12, pp. 1378-1385.

3. Belien, J., 2021, "20 years of INFORMS Transaction on Education," INFORMS Transactions on Education, Vol. 21, No. 2, pp. 65-66, https:// doi.org/10.1287/ited.2019.0242.

4. Cochran, J. J., 2019, "Writing and Teaching Analytics with Cases," INFORMS Analytics Body of Knowledge, Wiley.

5. Drake, M. J., 2019, "Teaching OR/MS with Cases: A Review and New Suggestions," INFORMS Transactions on Education, Vol. 19, No. 2, pp. 57-66, https://doi.org/10.1287/ited.2018.0204.

6. Penn, M. L., Currie, C. S. M., Hoad, K. A. and O'Brien, F. A., 2016, "The use of Case Studies in OR Teaching," Higher Education Pedagogies, Vol. 1, No. 1, pp. 16-25, http://dx.doi.org/10.1080/23752696.2015.1134201. 

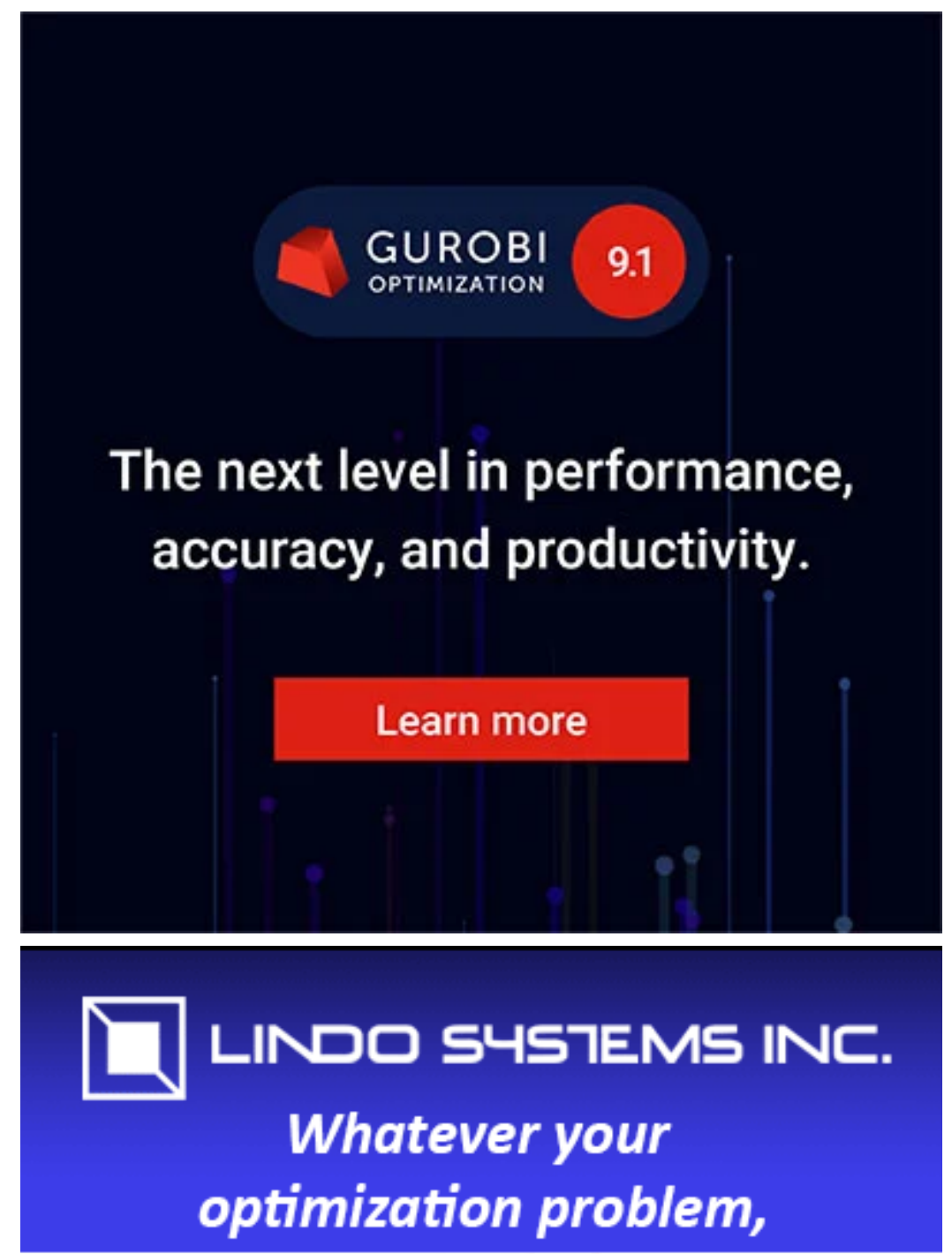

\section{Unit Commitment,}

\section{Marketing,}

Recipe Blending,

We can solve it. 


\section{ㄴINDO S4SㅌM INC.}

\section{Whatever your optimization problem,}

supply chain,

\section{Unit Commitment,}

Marketing,

Recipe Blending,

\section{We can solve it.}

\section{Learn more}

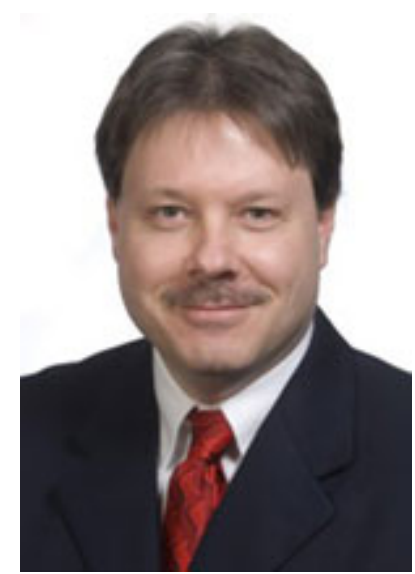

James J. Cochran

(jcochran@cba.ua.edu)

James $\mathrm{J}$. Cochran is associate dean for research and professor of applied statistics at the Culverhouse College of Business, University of Alabama. Cochran is also a co-founder of Statistics Without Borders and chair of the OR/MS Today Committee.

\section{Jeroen Beliën}

Jeroen Beliën, Ph.D., is a professor in the Research Centre for Operations Management (OM), Brussels Campus, at KU Leuven. He serves as the editor-in-chief of INFORMS Transactions on Education (ITE).

\section{SHARE: $\mathbf{f}$ in $\boldsymbol{y} \square$}

Keywords: Issues in Education; Case Competition 


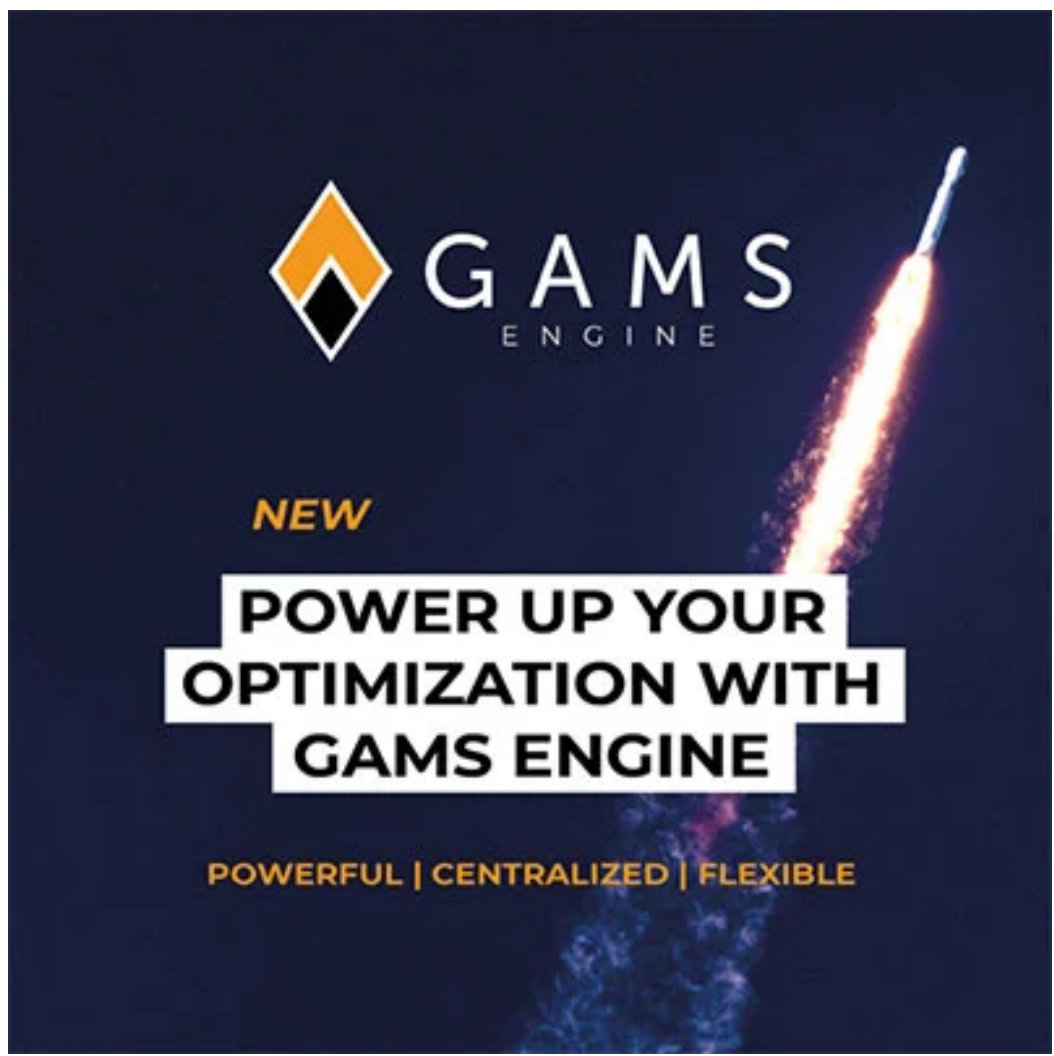

ANALYTIC SOLVER+RASON

PRESCRIPTIVE \& PREDICTIVE ANALYTICS TOOLS FOR YOUR WHOLE TEAM

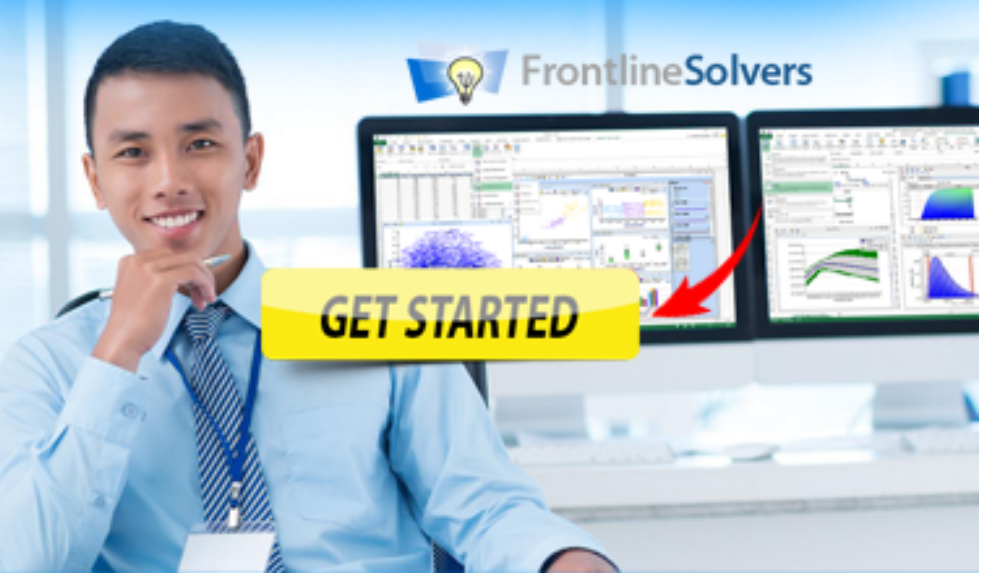




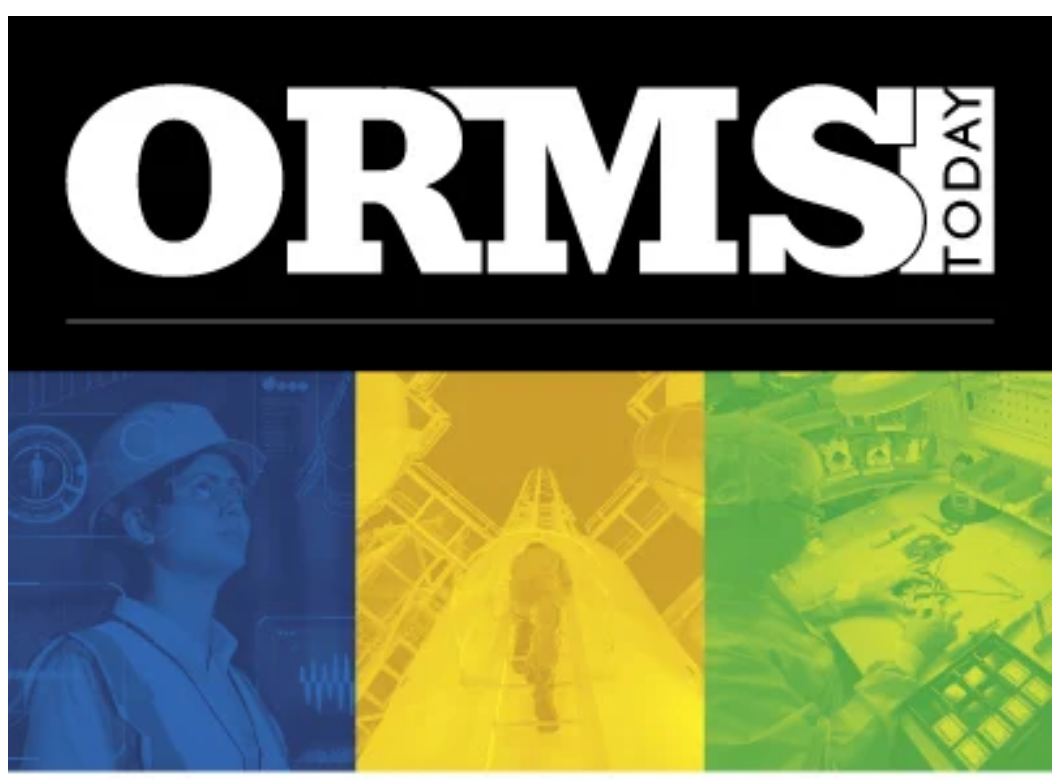

\section{ADVERTISE TO REACH TOP OR/MS AUDIENCES!}

\section{Sign Up for INFORMS Publications Updates and News}

Sign Up

SUBSCRIBE CONTACT ADVERTISE 


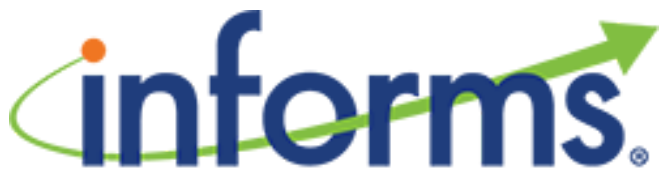

\title{
25TH ANNIVERSARY
}

The Institute for Operations Research and the Management Sciences

5521 Research Park Drive, Suite 200

Catonsville, MD 21228 USA

phone 1 443-757-3500

phone 2 800-4INFORMS (800-446-3676)

fax 443-757-3515

email informs@informs.org

\section{Get the Latest Updates}

\author{
Email Address
}

\section{Sign Up}

Discover INFORMS

Explore OR \& Analytics

Get Involved

Impact

Join Us

Recognizing Excellence

Professional Development

Resource Center

Meetings \& Conferences

Publications

About INFORMS

Communities

PubsOnLine

Healthcare Conference 2021

Certified Analytics Professional

Career Center

INFORMS Connect 
Follow INFORMS on: Twitter f Facebook in Linked In 